\title{
La encrucijada de Ia democracia chilena: una aproximación conceptual a la desafección política*
}

\section{The Crossroads of Chilean Democracy: A Conceptual Approach to Political Disaffection}

\author{
Roberto Mardones A.**
}

Recibido: 17/11/2013

Aprobado Evaluador Interno: 24/11/2014

Aprobado Evaluador Externo: 23/02/2014

\section{Resumen}

Este artículo, según la importancia y complejidad que tiene la precisión conceptual en las ciencias sociales, tiene por objetivo someter a discusión el concepto de desafección política. Este concepto corresponde a un fenómeno que se identifica a mediados de los noventa en Chile tras el retorno a la democracia. Si bien la literatura ha dado cuenta del fenómeno, éste carece de una definición precisa; desde nuestra perspectiva, no ha sido contextualizado de una manera que presente los atributos necesarios que lo ajusten a la realidad chilena para poder observarlo con claridad.

\section{Palabras clave:}

claridad conceptual; desafección política; tridimensionalidad de la política; participación; Chile

\section{Abstract}

This article, according to the importance and complexity conceptual precision has for Social Sciences, is to submit for discussion the concept of political disaffection. This corresponds to a phenomenon that is identified in the midnineties in Chile, after the return to democracy. Although the literature has noticed the phenomenon, it lacks a precise definition; in our point of view, the concept has not been contextualized in a way that presents the necessary attributes that adjust it to Chilean reality in order to be able to observe it clearly.

\section{Keywords:}

conceptual clarity; political disaffection; threedimensionality of the policy; participation; Chile

doi:10.11144/Javeriana.PAPO19-1.edca

* Artículo de reflexión

** Doctor en Ciencias Sociales, Universidad Nacional de Cuyo, Argentina; Magíster en Ciencia Política, Universidad de Chile; Profesor de historia, geografía y educación cívica, Universidad Austral de Chile. Académico del departamento de sociología y ciencia política de la Universidad Católica de Temuco. Correo electrónico: rmardones@uct.cl. 



\section{Introducción}

Una de las cuestiones básicas que permiten investigar un fenómeno es definir claramente el o los conceptos a utilizar, esto "se trata de una fase importante de la investigación, ya que la posibilidad de realizar inferencias a partir de la misma a otros casos similares depende de la utilización de una definición explicita de los conceptos y de la realización de una medición correcta de los mismos" (Anduiza, Crespo y Méndez, 1999, p. 33). No obstante, es importante considerar que, tal como dijimos, esto es una labor compleja, entre otras razones, "por el simple hecho de que involucran a actores guiados por múltiples valores que no pueden reducirse a un solo principio de conducta que supuestamente gobierna la actitud de todos los actores" (Nohlen, 2008, p. 10).

Los conceptos son fundamentales para comprender la realidad dado que "la realidad social no se percibe nunca de forma directa, sino siempre a través de conceptos que estructuran lo observado por diferentes observadores de manera diferente" (Nohlen, 2008, p. 9). Tal como dice Sartori (2000), los conceptos son unidades de pensamiento, de pensamientos que expresamos a través de términos que corresponden a unidades lingüísticas, las cuales tienen un contenido y una proyección semántica, y por ende, una significación. Por tanto, entre términos y conceptos existe una relación de significación.

Ahora bien, el significado de un término se establece a partir de una definición que permite generar cierta uniformidad en el uso. En este caso, el concepto a tratar es el de desafección política, extrapolado a la realidad chilena, sin haber producido, desde nuestra perspectiva, un ajuste conceptual y contextual.

La desafección política ha sido ampliamente estudiada como fenómeno en Europa y Estados Unidos. ${ }^{1}$ En el caso chileno, surge tras el retorno a la democracia y, por lo visto, se expandió en los últimos veinte años de gobiernos democráticos. Así, desde mediados de los 9o's, la literatura sociopolítica chilena dio cuenta de él y de su existencia sin arribar a una definición en particular.

Es por lo anterior que, si bien el tratamiento extensivo y cabal del tema no es posible en las presentes líneas, nuestro objetivo es, a partir de un breve ejercicio de análisis bibliográfico, discutir con algunos autores chilenos y extranjeros que se han referido al fenómeno y aproximar una respuesta tentativa a la siguiente pregunta: ¿qué es la desafección política? Esto nos permitirá, posteriormente, realizar una elaboración conceptual adaptada al contexto de Chile.

\footnotetext{
${ }^{1}$ Fue identificado hacia finales de los sesenta y principio de los setenta en Europa y Estados Unidos y relacionado con crisis del sistema democrático, pérdida de confianza en las instituciones, descontento, cuestiones expuestas, por ejemplo, en el libro de Pharr, S. y Putnam, R. (2000). Disaffected democracies: What's troubling the trilateral countries? New Jersey: Princeton University press.
} 


\section{Aclaración previa}

Partimos la discusión con una definición tomada del diccionario, una definición declarativa que cumple con un imperativo: "eliminar los malos entendidos; con este fin, cada autor debe declarar con que significado utiliza una palabra determinada" (Sartori, 2000, p. 67) para lo cual recurrimos a la Real Academia Española (2001). Aquí encontramos que desafección se relaciona con "mala voluntad", en tanto que alguien que siente desafecto, "no siente estima por algo o muestra hacia ello desvío o indiferencia". Este punto de partida resulta ser interesante ya que se dirige efectivamente al meollo del asunto, en este caso, la falta de estima e indiferencia hacia la política y la mala voluntad con respecto a aquella actividad, lo cual queda evidenciado en distintos barómetros y encuestas.

Así pues, esta definición nos acerca a nuestro objeto de estudio, pero para explicar el fenómeno es necesario profundizar un poco más. Esto, toda vez que el significado de la palabra no da cuenta del fenómeno y no lo explica, pues está asociado a la política en su tridimensionalidad; por ende, podríamos afirmar que no es posible aplicarlo a otra realidad sin primero observarla.

¿Se puede extrapolar entonces? ¿El desafecto chileno es el mismo desafecto europeo? ¿Se puede establecer un punto de comparación? La respuesta es no porque aquí entra a tallar la historia y el contexto, por lo que es necesario adaptar el concepto, hacerlo menos abstracto, darle una mayor cantidad de atributos relacionados con la realidad particular, como dice Lechner "nuestra delimitación de lo posible -y de las posibilidades de la democracia - depende finalmente de nuestros mapas cognitivos con los cuales interpretamos la realidad social” (1994, p. 35). De esta manera, se evita el estiramiento conceptual que es el "resultado del deseo de muchos estudiosos de hacer 'viajar' a los conceptos y de adaptarlos a contextos diferentes" (Anduiza, Crespo y Méndez, 1999, p. 37), esto sin pasarlos por el cedazo correspondiente.

En función de lo anterior, tomaremos en primera instancia a cuatro autores chilenos que se han referido al tema desde ópticas similares y argumentos complementarios, aunque también hay otros autores que lo han tratado. ${ }^{2}$ En un segundo momento, trataremos la temática con dos autores extranjeros.

\section{Luces y sombras del concepto en Chile}

Parker sitúa su análisis en la juventud, relaciona abstención con desafección, definiéndola como "desinterés creciente por la política" y utilizando como indicador "la escasa

\footnotetext{
${ }^{2}$ Tenemos a Norbert Lechner, que habló de un cansancio prematuro con la democracia; Carlos Hunneus y José Joaquin Brunner, desde ópticas distintas, se acercan al tema del malestar en democracia; Tomás Moulian de la sociedad del consumo entre otros. También es necesario precisar que no todos utilizaron el concepto de desafección política, más bien dentro del argumento general desprendemos que se refieren a él mientras que otros, como los que trataremos, se refieren explícitamente al fenómeno.
} 
inscripción de los jóvenes en los registros electorales y en la escasa voluntad de participación activa en política" (2003, p. 1). En el tratamiento que hace este autor del tema se nota la influencia del contexto, esto toda vez que asume que la actitud desafecta sería coherente con un escenario político en el cual estén vigentes los denominados poderes fácticos, ${ }^{3}$ los cuales distorsionan el sistema político, es decir, el fenómeno de la desafección se correlacionaría positivamente con la existencia de un sistema político alterado.

Hay dos cuestiones muy importantes en el párrafo anterior; por un lado, aunque se podría pensar que al momento de terminar formalmente con dichos poderes, la desafección, sobre todo entre los jóvenes, segmento al que apunta el autor, debería haber comenzado a bajar, esto no es así: de hecho, la no inscripción y la abstención del voto, aumentan proporcionalmente. Por otro lado, este fenómeno se relaciona exclusivamente con el acto eleccionario. Inscribirse y votar no son operaciones que se entienden como "participación activa en política" sino que, por los argumentos utilizados, inferimos que se refiere a una participación política más bien formal, es decir, dentro de los organismos tradicionalmente reconocidos como los partidos políticos, sindicatos, federaciones, etc.

Complementario con lo anterior, Toro (2008) realiza un análisis sobre juventud y política en donde los temas centrales son la desafección y la participación política. Si bien el artículo se refiere en reiteradas oportunidades al fenómeno, no hay una definición del mismo, este es relacionado con el alejamiento de la política de los anhelos juveniles, lo que lleva a un desencanto juvenil que podría producirse ante la inconsistencia entre expectativas y satisfacción inmediata de demandas. Además, al igual que en Parker, este fenómeno se vincula con cuestiones de orden institucional, particularmente con el voto y el declive de la inscripción electoral. Este tema es recurrente en la obra de Toro desde hace algún tiempo, pues en otro artículo afirma que "la desafección juvenil hacia las elecciones se ha transformado en uno de los temas de mayor trascendencia en el debate internacional" (2007, p. 101) en donde, nuevamente, la participación se reduce a participación electoral, asumiendo que "la escasa participación electoral de los jóvenes ha llegado a reducir su capacidad para hacer valer sus demandas e influir sobre la priorización de las políticas públicas" (2007, p. 104). Desde nuestra perspectiva el autor hace dos afirmaciones que son muy optimistas: "hacer valer demandas" e "influir en la priorización de las políticas públicas”, cuestiones que creemos están no solamente fuera del alcance de los jóvenes sino de cualquier ciudadano.

\footnotetext{
${ }^{3}$ Hasta la reforma a la Constitución realizada durante el gobierno de Ricardo Lagos, en 2005, en Chile existían senadores designados y vitalicios, los comandantes en jefe de las fuerzas armadas y carabineros eran inamovibles, el consejo de seguridad nacional, compuesto por los cuatro comandantes en jefe de las fuerzas armadas y de orden podía autoconvocarse, entre otras cosas. Tomás Moulian le denomina "jaula de hierro".
} 
En la misma línea (juventud, desafección, participación, elecciones) está el artículo de Madrid (2005) en donde se habla de apatía o apoliticismo, lo cual el autor define como "la desvinculación de ciertos ciudadanos del sistema político formal e institucionalizado; es decir, como la desvinculación con la política más que con lo político” (p. 5). De esta definición llama nuestra atención el uso de los conceptos la política y lo político. Por una parte, los datos revelan que el ciudadano se siente desvinculado de la política en general, no sólo de lo formal e institucionalizado. Tomando como referencia a los jóvenes, la última encuesta de juventud realizada por el Instituto Nacional de la Juventud ${ }^{4}$ (INJUV) nos indica que como ha sido la tendencia en la última década, la importancia que le asigna y la confianza que tiene este segmento de la población en la política formal e institucional está en niveles muy bajos, pero tampoco se evidencia el surgimiento de nuevas formas de participación política, como lo indica la tabla a continuación.

Tabla $1^{5}$ : Jóvenes y participación

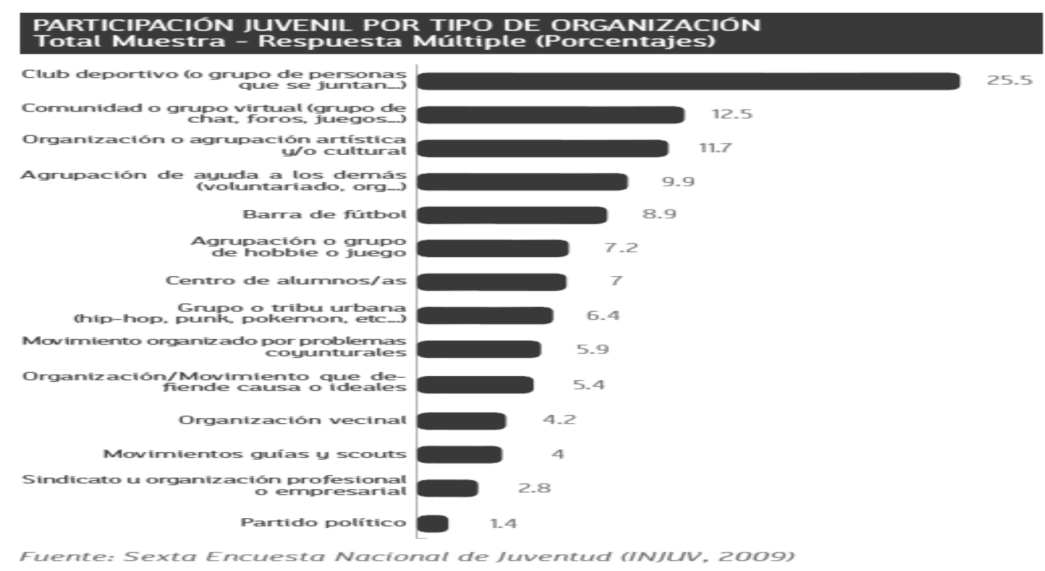

Por otra parte, la definición de Madrid expone dos dimensiones de la política, "politics" (la política) y "policy" (lo político), conceptos que no están bien utilizados pues la primera alude a la dimensión subjetiva y la segunda a la objetiva. La primera influye en la segunda, la genera, "el término la política apunta, fundamentalmente, a una actividad humana con proyección social; el vocablo lo político alude a un aspecto de la realidad social, que se crea, conserva y transforma por la actividad política” (Ferrando, 1976, p. 673). Cuando Madrid hace alusión a la política se refiere a "la forma tradicional de acción en el campo político de carácter institucional” (2005, p. 5), lo que más bien corresponde a "policy", es decir la forma, la arquitectura fija, la política como organización. Por ende,

\footnotetext{
${ }^{4}$ Sexta encuesta nacional de juventud, INJUV, 2009.

${ }^{5}$ Obtenida de la Sexta encuesta nacional de juventud, INJUV, 2009.
} 
la definición dada al principio sería incorrecta en tanto que la relación que se establece en ella es errónea.

$\mathrm{Al}$ igual que en los otros autores, el tema es abordado por Madrid desde una óptica institucional, aunque en este caso no se plantea directamente que apatía sea desafección, pues cuando se refiere a la primera habla de "despolitización en términos de una desafección de los registros" (2005, p. 11). Si por registros el autor se refiere a registros electorales, esto restringiría aún más el concepto, pues implicaría que desafección es no inscribirse.

Entonces, hay dos cosas claras: la primera, que no hay una sola manera de referirse a la desafección, y la segunda, que en gran medida ésta es relacionada con lo institucional, pues el cuestionamiento de los autores es cómo afecta a las instituciones el que los jóvenes no se inscriban y que los inscritos se abstengan de votar. Ahora bien, es correcto centrarse en los jóvenes toda vez que corresponden al recambio, pero el problema es que la desafección es transversal, atraviesa a todos los grupos etéreos, no distingue entre sexos y afecta a todas las dimensiones de la política.

De alguna manera, tal y como afirma Morales (2008), en Chile se da una inconsistencia en cuanto a las fortalezas que presenta el sistema político chileno y las "debilidades internas asociadas, principalmente, a la participación ciudadana y al accountability” (p. 162). Desde nuestro punto de vista, este autor apunta a algo nuevo que finalmente no desarrolla; teniendo en cuenta que el fenómeno de la desafección política está asociado a países desarrollados con democracias consolidadas en las cuales han surgido otras formas de expresión ciudadana como algo positivo, "el caso de Chile parece alejarse de esta lógica. La baja participación no sólo es política, sino que también es comunitaria” (p. 165), lo cual queda refrendado en la tabla 1. Si la vemos por macro temas, no hay gran participación en términos sociales, comunitarios, culturales o políticos.

Lo anterior nos dirige tal vez a uno de los problemas más graves. El efecto más complejo de la desafección en Chile es que la ciudadanía deja completamente de lado la actividad política en sus tres dimensiones, se produce inmovilismo. Así pues, un ciudadano desafecto "puede quedar expuesto a las políticas clientelares de los partidos" (2008, p. 166), cuestión que no está muy lejos de ser cierta, debido a que el apoyo a los partidos está en niveles muy bajos, tal como indica la tabla 1, pero siguen siendo éstos los que controlan, organizan y canalizan la oferta electoral.

En este breve repaso, una cuestión que marca tendencia con respecto a la bibliografía utilizada por los autores mencionados es que está ligada a la literatura anglosajona, lo cual podría ser síntoma de la extrapolación y del estiramiento conceptual. Otro factor, probablemente el más importante, está relacionado con que el énfasis está en lo institucional. Por ejemplo, el problema relativo a la no inscripción en los registros electorales y el fenómeno de la abstención son cuestiones relevantes que nos muestran un grado importante de mala voluntad e indiferencia hacia la política, que, además, es medible, 
pero ¿̇reduciremos la política a lo formal - institucional? ¿La participación política sólo es participar electoralmente? ¿El ciudadano que participa es el ciudadano que vota? Nuestra respuesta es no a todos los interrogantes, toda vez que está en juego la posibilidad de tener una democracia mejor, pues "la esencia de la democracia radica en que es capaz de empoderar a los ciudadanos comunes" (Welzel e Ingehart, 2009, p. 176). Esto implica que no se trata solamente de tener una serie de procedimientos formales que en apariencia permitan la participación como las elecciones, se requiere de un ciudadano comprometido que no cuestione la legitimidad de la democracia, lo que, a decir verdad, es el trasfondo del problema, tal como lo indican las siguientes gráficas.

\section{Gráfica 1: ${ }^{6}$ Evolución jóvenes que piensan que le democracia es preferible a cualquier otra forma de gobierno.}

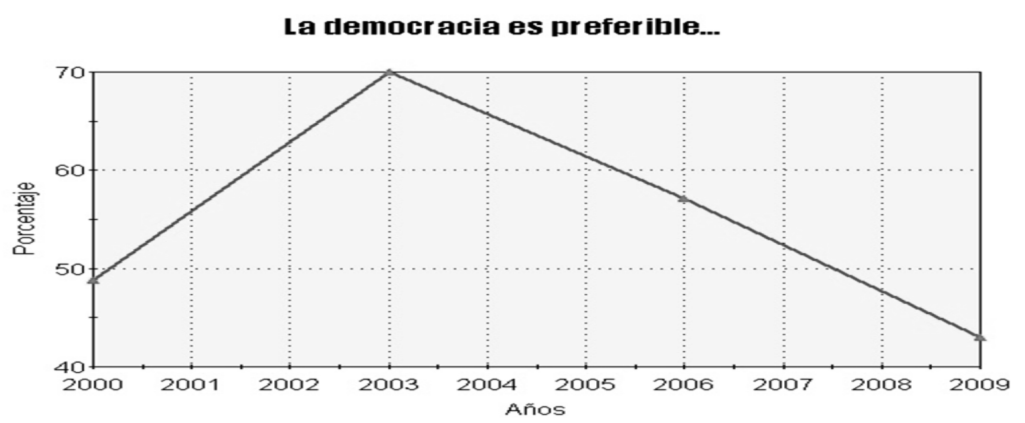

\section{Gráfica 2:7 Evolución jóvenes que piensan que da lo mismo y que a veces es preferible un gobierno autoritario.}

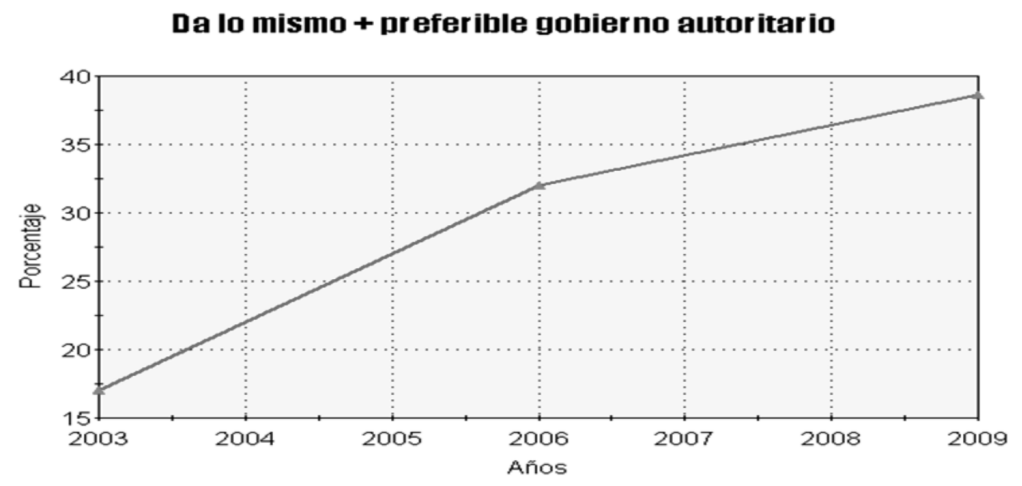

\footnotetext{
${ }^{6}$ Con base en datos obtenidos de la tercera (2000), cuarta (2003), quinta (2006) y sexta (2009) encuesta nacional de juventud aplicadas por el INJUV.

${ }^{7}$ Con base en datos obtenidos de la cuarta (2003), quinta (2006) y sexta (2009) encuesta nacional de juventud aplicadas por el INJUV.
} 
Las gráficas son elocuentes. Entre la juventud, aunque no solamente entre ellos, existe una deslegitimación de la democracia como sistema de gobierno. Una posible explicación podría ser que, si bien se destaca la estabilidad y los logros económicos de Chile, esta sigue siendo una sociedad profundamente injusta, desigual y subdesarrollada en muchos aspectos. Un ejemplo de ello fueron las movilizaciones estudiantiles del año 2011 que ponen de manifiesto una de las brechas basales: el acceso a la educación de calidad. ¿Por qué? Porque se necesita una buena educación para tener ciudadanos informados, con opinión e interesados en el quehacer público. Sólo así se puede presionar a la democracia representativa liberal y su principal instrumento, los partidos políticos, que, productos del proceso de profesionalización por el cual han pasado, se han desligado cada vez más de la ciudadanía. Esto, en algún momento, nos permitirá avanzar hacia una democracia efectiva y no solamente electoral la cual se puede dar en casi cualquier lugar (Welzel e Inglehart, 2009).

La ciudadanía debe involucrarse y tener "espíritu público”, aunque no es posible que gobierne, "es preciso que la minoría dirigente sea mantenida a raya. La función de las masas en democracia no es gobernar, sino intimidar a los gobernantes" (Ostrogorsky, 2008, p. 41). Este es un notable apunte de un clásico de la democracia y los partidos políticos que nos indica que manteniendo las distancias y asumiendo la diferencia de contexto, es absolutamente importante el involucramiento ciudadano, no solamente en la dimensión institucional sino también en la no institucional.

\section{¿Desafección o alienación?}

Ahora bien, para entrar al segundo momento pensamos que una buena aproximación a la discusión del concepto de desafección política es tomar otra definición, en este caso, la de Torcal (2001). A diferencia de la definición expuesta anteriormente, esta alude al fenómeno para el caso europeo, pero integra cuestiones que consideramos se pueden rescatar en el caso chileno. Torcal dice que la desafección política corresponde a un "sentimiento subjetivo de ineficacia, cinismo y falta de confianza en el proceso político, políticos e instituciones democráticas que generan distanciamiento y alienación pero sin cuestionar la legitimidad del régimen político" (p. 3). Primero que todo, consideramos que es importante que en esta definición se parte de la base de que el fenómeno es un "sentimiento subjetivo", pues para comenzar la discusión acerca del tema es fundamental asumir su condición subjetiva, elemento crucial de la vida en sociedad. Claro está que el mundo es una construcción cognitiva, nuestro conocimiento proviene, en gran medida, del sentido común cotidiano que debemos comprender para generar un conocimiento de carácter científico; de ahí la importancia de la claridad conceptual, de la definición clara de nuestro objeto de estudio.

Por otra parte, esta definición contiene tres ideas que, en nuestra opinión, son llamativas y nos dan una pauta de análisis: el "cinismo", la "alienación” y que la desafección 
“no implica cuestionamiento al régimen”, factores que analizaremos en función de los datos existentes para la realidad chilena, lo cual nos permitirá visualizarla e ir avanzando en una conceptualización propia.

En cuanto al cinismo, este está referido a la actitud que toma la clase política respecto del ciudadano. En este sentido, Ludolfo Paramio (1999) alude al cinismo político diciendo que es un rasgo característico de la desafección política y que se puede definir como una forma de actuar en que se percibe que "los políticos no se ocupan de los problemas de la gente común, sino de sus propios intereses" (p. 84). Esta actitud, de una u otra forma, mina la base identitaria de los ciudadanos hacia la clase política.

En Chile, el cinismo se ve reflejado en que "una mayoría relativa de los chilenos sostiene que los partidos son grupos cerrados" (Luna y Seligson, 2007, p. 161) o, como lo indica la Encuesta Nacional sobre partidos políticos y sistema electoral (Cieplan et $a l, 2008$ ), quienes creen que los partidos políticos privilegian sus intereses sobre los del país llega a un 55\%, y los que creen que éstos no representan los intereses de la gente a un $44 \%$, lo que indica que el ciudadano promedio siente que los partidos políticos operan para su beneficio y el del pequeño entorno que los rodea.

Lo anterior tiene un impacto que se expresa tanto en el interés que presentan los ciudadanos hacia la política, como en la confianza que tienen en las instituciones, particularmente en los partidos políticos, como lo indican las siguientes gráficas:

\section{Gráfica 3:8 Interés en la política}

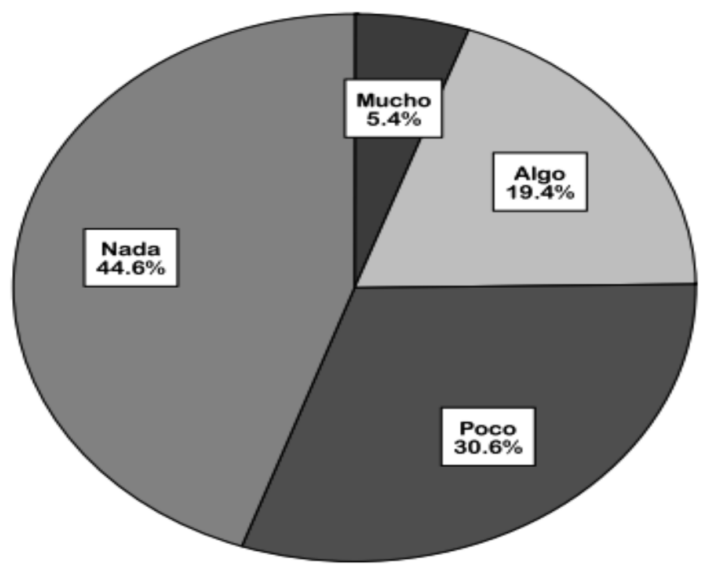

Interés en la Política

Fuente: Barómetro de las Américas por LAPOP

\footnotetext{
${ }^{8}$ Obtenido de: Luna y Zechmeister, p. 134.
} 


\section{Gráfica 4:9 Confianza en las instituciones}

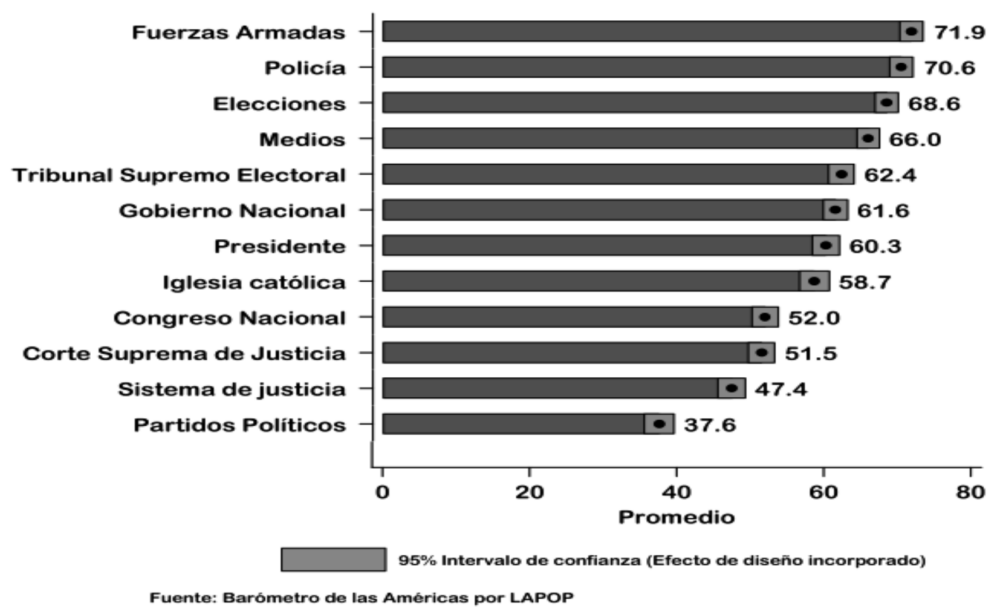

La gráfica 3 da cuenta de la situación del interés por la política, y queda en evidencia un desinterés total pues si sumamos las opciones "nada" y "poco" da un expresivo $75,2 \%$ contra el 24,8\% de "mucho" más "algo". Con respecto a la confianza, en la gráfica 4, se constata una situación que por lo menos puede ser tildada de paradójica. Las instituciones que se suponen son el sostén de la democracia ocupan los últimos cuatro lugares; en tanto, las fuerzas armadas y la policía están al principio, siendo Chile uno de los países que vivió una de las dictaduras más cruentas. ¿Algo ocurre, no?

Igualmente, todo indica que se podría hablar de un cinismo ciudadano. Desde este punto de vista, y siguiendo la reflexión de Torcal, es posible que se presente desafección por satisfacción con las autoridades, es decir, que "la gente tiende a participar menos cuanto más satisfechos están con el funcionamiento de la democracia” (2000, p. 39). Esta situación se puede observar en Estados Unidos, pues los niveles de participación son bajos en una población que, se supone, maneja información y entiende de política: como sus intereses están seguros, su participación no es necesaria.

Según lo anterior, la pregunta es si esto podría ajustarse a la realidad chilena, ¿̇erá que los ciudadanos chilenos no participan por estar satisfechos con la democracia? Los datos dicen que no, aunque los chilenos sienten que este sistema funciona mejor en su país que en otros países vecinos, se muestran muy poco satisfechos. Algunos datos de Latinobarómetro (2011) indican que el nivel de satisfacción con la democracia en Chile llega al $32 \%$, siendo $39 \%$ el promedio para Latinoamérica, en tanto quienes piensan que se gobierna para el bien de todo el pueblo presenta una baja de 26 puntos porcentuales entre 2010 y 2011, siendo la más abultada en la región.

${ }^{9}$ Obtenido de: Luna y Zechmeister, p. 90. 
Así pues, no sería incorrecto pensar que los chilenos ven su democracia sólida en términos comparados a la vez que se muestran críticos con su funcionamiento, lo cual nos parece correcto. No obstante, para que esto fuera así, tendría que haber una intención en la ciudadanía de mejorar la democracia, preocuparse por temas como la diversidad, la integración, la incorporación de nuevos grupos, etc. Sin embargo, esto no está ocurriendo, al contrario, existe una suerte de inmovilismo y contradicción en la percepción de lo que la democracia implica. Por ejemplo, se asume que las marchas, protestas y manifestaciones en la calle "son normales en democracia" ( $73 \%$, el promedio de Latinoamérica es 63\%) pero a la vez, mayoritariamente, la opinión es que "sólo producen desmanes y destrozos” (71\%, el promedio de Latinoamérica es 49\%) y sólo el 11\% afirma haber asistido a manifestaciones autorizadas (Latinobarómetro 2008, p. 105).

Por tanto, podemos deducir que en el caso de Chile no es posible decir que exista una desafección por satisfacción. El cinismo ciudadano podría radicar en lo que se dice (cómo se responde a las encuestas, por ejemplo) contra lo que se hace en la práctica cotidiana. Es decir, resulta fácil criticar desde la comodidad de la casa pero complicado salir a expresar el descontento, es más cómodo y se arriesga menos esperando a que otros salgan y luego recibir los beneficios de esa movilización; quizás estemos frente a un potencial "free raider", un ciudadano que evalúa su acción en torno de la díada costo - beneficio, muy propio de la teoría de la elección racional.

Asimismo y según los datos, existe una acción pendular de la ciudadanía que se ve afectada por contextos y momentos. Como ejemplo de esto podemos referirnos a la encuesta Adimark (abril de 2009) en donde se indica que la aprobación a la Presidenta Bachelet ${ }^{10}$ estaba en un $67 \%$, lejos de ese $35 \%$ de 2008 ; la aprobación al gobierno pasó de un $26 \%$ (septiembre de 2008) a 53,6\% (abril de 2009), en tanto que la desaprobación bajó de $59 \%$ (septiembre de 2008) a 35\% (abril de 2009); evidentemente hay una inconsistencia, disonancia cognitiva, que podría hacer parte de este cinismo ciudadano. En el caso del presidente Piñera también podríamos decir lo mismo: al inicio de su gobierno, que estuvo marcado por el terremoto de febrero de 2010 y a mediados de año por el caso de los mineros atrapados, bordeaba el 52\% de aprobación llegando a 54\% y hoy está estancado en el $30 \%$. Por lo tanto, debemos decir que, si bien concordamos con la idea de que existirían dos vertientes para el cinismo, la política y la ciudadana, con lo que no estamos de acuerdo es con que el caso del cinismo ciudadano se encuentre relacionado con la satisfacción.

\footnotetext{
${ }^{10}$ Terminó su gobierno con un alto grado de aprobación ciudadana al igual que su gobierno en menor medida; este no se traspasó al candidato de su coalición, la concertación de partidos por la democracia, y terminó siendo electo presidente el candidato de la oposición, quien en el mes de junio de 2011 obtuvo su menor aprobación, 36\%, al igual que su gobierno.
} 
En cuanto a la alienación, y siguiendo la reflexión de Paramio (1999), esta se podría definir desde dos puntos de vista en función de la profundidad que presenta: uno estaría relacionado con la apatía y el otro sería la alienación propiamente dicha. En el primer caso estaríamos hablando de que "existe una indiferencia hacia la política y los partidos que puede ser compatible con la participación electoral esporádica” (p. 83). La afirmación anterior concuerda con lo que ocurre en Chile, donde efectivamente hay indiferencia hacia la política y hacia los partidos políticos. Respecto a la participación electoral esporádica, si lo traducimos a la realidad chilena tendríamos que decir que más que una participación electoral esporádica, producto del esquema en el cual la inscripción era voluntaria y el voto obligatorio, ${ }^{11}$ lo que se dio fue la no inscripción y la abstención. En cuanto a lo primero, estaban fuera del padrón más de cinco millones de potenciales votantes de los cuales un porcentaje importante correspondía a gente joven, ${ }^{12}$ produciéndose un envejecimiento paulatino del padrón electoral Sólo entre 2005 y 2008, según datos del servicio electoral, el padrón disminuyó aproximadamente en 110.000 votantes, y para el 2009 aumentó en $185.000 .{ }^{13}$ Ahora bien, como indica la gráfica a continuación, la caída es constante desde 1992, acompañado de un envejecimiento de la población.

\section{Gráfico 4: ${ }^{14}$ Envejecimiento de la población y padrón electoral}

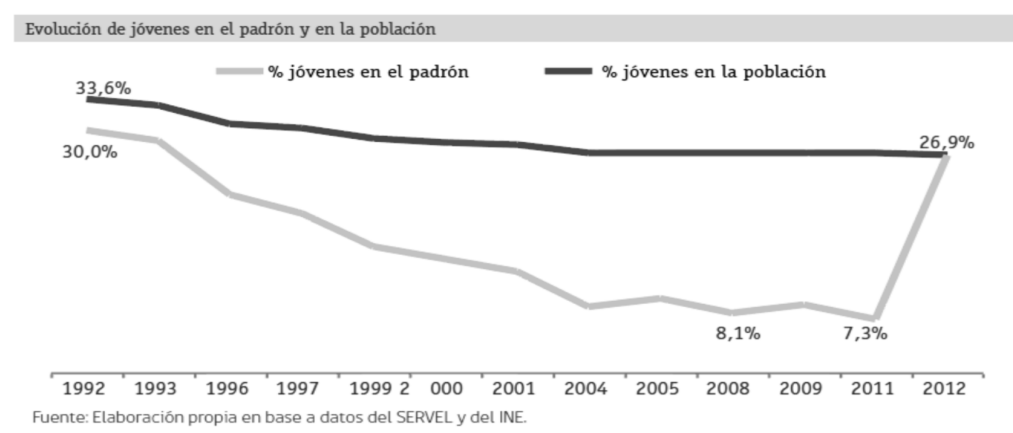

Por otro lado, según el Tribunal Calificador de Elecciones, (TRICEL), en la elección de diciembre de 2009 no fueron a votar 1.058.552 personas, lo cual corresponde al 12,77\% del total de inscritos, que aunque no es un porcentaje muy alto no deja de ser llamativo,

\footnotetext{
${ }^{11}$ La situación cambia a partir del 31 de enero de 2012 cuando entra en vigencia la ley 20568 que instala la inscripción automática y el voto voluntario.

12 Con respecto a los inscritos, si consideramos como jóvenes al grupo etario que va entre los 18 y 29 años, para las elecciones llevadas a cabo en 2009 estos correspondían al 18, 47\% del total del padrón. Disponible en: www.servel.cl

${ }^{13}$ Para la elección de alcaldes y concejales de 2008 el padrón era 8.110.265, en tanto que para las elecciones presidenciales y parlamentarias de 2009 fue de 8.285.186. Disponible en: www.servel.cl ${ }^{14}$ Instituto nacional de la juventud (2012) "Jóvenes y las próximas elecciones municipales", p. 8.
} 
sobre todo teniendo en cuenta que quien no vota se expone a ser sancionado (multa pecuniaria o encarcelamiento). Para que esto no ocurra se debe hacer un trámite que implica dejar constancia de la falta, proceso que puede ser tanto o más complicado que ir a votar.

Lo anterior concuerda con otro dato que dice que "quienes menos participan electoralmente en el sistema político chileno (tal vez porque no se encuentran bien interpretados por la estructura actual de la competencia partidaria) son quienes poseen mayores niveles de participación en protestas" (Luna y Seligson, 2007, p. 188). Ahora bien, esto último se da dentro del contexto chileno en el que los niveles de participación en protestas en general son muy bajos pero con tendencia más alta entre el segmento joven, que es a lo que se refiere el estudio. El mismo estudio concluye que no se trataría de apatía sino que más bien "parecería tratarse de un segmento de la población que se encuentra alienado respecto del funcionamiento actual del sistema político chileno” (Luna y Seligson, 2007, p. 188) con lo cual estamos de acuerdo, aunque nosotros consideramos que sí hay apatía en tanto la ciudadanía manifiesta indiferencia. Esto se ve reflejado en que los niveles de participación tanto convencionales como no convencionales, son insatisfactorios como para pensar que no hay apatía. Además, se debe apuntar hacia un tipo específico de participación, la participación política, y no a cualquier tipo de asociatividad sino a una que contribuya a la profundización de la democracia. Ahora bien, es cierto que apatía no es sinónimo de desafección, por lo que un ciudadano apático puede no querer movilizarse, ser abúlico, pero perfectamente puede tener opinión política. Sí estamos de acuerdo en que habría una alienación respecto del sistema político, producto de no sentirse interpretado ni identificado con la clase política, lo que estaría en consonancia con lo que plantea la definición de Paramio al relacionar apatía con alienación.

Por otra parte, la alienación propiamente dicha que se presenta como una alienación "respecto del sistema político y a los valores de la democracia, incluyendo la creencia en otras posibles formas de gobierno más eficaces o más justas" (Paramio, 1999, p. 83). Esto último resulta ser bastante complejo y está en la línea de lo ocurre en Chile, en tanto los estudios indican que entre la población cada vez toma más fuerza la idea de que cualquier forma de gobierno da lo mismo o que a veces un gobierno autoritario podría ser conveniente, por tanto, tal como se indicó más arriba, hay una alienación respecto del sistema político chileno. En este sentido la apatía y la alienación en el caso chileno serían complementarias.

En este punto, cabe destacar que no se percibe una distinción precisa entre alienación como apatía y desafección, ¿cuál es la diferencia entre ambos conceptos? La diferenciación que hacen Montero, Gunther y Torcal (1999) es más clara, ya que para ellos la alienación es un "sentimiento persistente de extrañamiento respecto de las instituciones, valores y líderes políticos existentes, y que tiene como consecuencia que los ciudadanos se consideren a sí mismos forasteros o intrusos" (p. 124). Consideramos que esta definición es coincidente con la segunda forma de alienación expuesta por Paramio, debido a que 
ambas apuntan hacia una cuestión más de índole sistémica en tanto interrelación de los distintos actores que participan dentro del sistema político en donde uno, el ciudadano, se siente desmedrado con respecto al otro, la clase política.

Asimismo, en las dos definiciones se alude a cuestiones de orden valórico. Recordemos que los sistemas políticos tienen como función asignar autoritativamente valores al sistema que deben ser cumplidos obligatoriamente. Es decir que las pautas valóricas sirven como hojas de ruta que permiten que el sistema se mantenga en equilibrio aunque esté sometido a constantes perturbaciones de los distintos ambientes que lo rodean, y lo que está ocurriendo es que el ciudadano siente que está fuera del sistema en general, que es ajeno a él, pero también se siente obligado a seguir sus pautas. Así pues, desafección sería "un conjunto de sentimientos mucho más difuso, y por el que los asuntos políticos son vistos como algo lejano, faltos de importancia o carentes de sentido" (Montero, Gunther y Torcal, 1999, p. 124); aquí la idea es que la desafección tiene como sustrato una serie de actitudes con respecto al sistema político que se identifican con el desinterés, la desconfianza y el cinismo políticos.

Según lo expuesto anteriormente, nos parece que a partir del planteamiento de los autores, desafección y alienación son conceptos que suponen niveles distintos, la pregunta es ¿̇cuándo estamos frente a uno u otro fenómeno? o ¿̇cuándo o cómo se pasa de desafección a alienación?, sobre todo si asumimos que esta última no solamente supone una falta de confianza en las instituciones y un alejamiento de la política sino también "un sentimiento de incapacidad para poder influir en el sistema y de que el sistema, a su vez, responda a las demandas de los ciudadanos" (Torcal, 2005, p. 1). Es decir que se percibe una imposibilidad de cambiar el curso de las cosas, y por tanto, si el esfuerzo no se ve recompensado, lo más probable es que deje de existir. Según el Programa de Naciones Unidas para el Desarrollo, para el individuo esta situación "representa, ante todo, no tener confianza en poder cambiar el curso de su vida o en poder incidir sobre la marcha del país. En consecuencia, este tipo de personas tiende a retrotraerse del ámbito político" (2003, p. 112). Lo anterior refuerza el interrogante acerca del límite entre una cosa y otra, y de hecho ese retrotraerse de lo político es muy parecido al "extrañamiento" y por ende, la discusión no está cerrada del todo.

Finalmente, el tercer punto en discusión acerca de la definición de Torcal (2005), es la que dice relación con la idea de que la desafección "no implica un cuestionamiento al régimen", de hecho se refiere a una "desafección democrática”, la cual tiene como características "la existencia de un apoyo mayoritario de los ciudadanos a sus regímenes democráticos y una gran moderación ideológica y tolerancia, conjuntamente con una falta de confianza en las instituciones, un alejamiento de la política, un sentimiento de incapacidad de poder influir en el sistema y de que el sistema, a su vez, responda a las demandas de los ciudadanos" (p. 1). A pesar de la existencia de dichas características, 
también se presenta apoyo y satisfacción con la democracia, lo que se comprueba con datos de otros barómetros y con un estudio hecho para el caso español, es decir que, si bien hay desafección política, la democracia no está en peligro.

Lo anteriormente expuesto es discutible para el caso Latinoamericano, y el chileno en particular, cuestión que el mismo autor salva al reconocer que existen democracias tradicionales y nuevas. En las tradicionales la desafección ha generado la aparición de nuevas formas de participación y ha disminuido "la utilización de mecanismos más convencionales de participación al tiempo que contribuye a aumentar la propensión a utilizar otros mecanismos alternativos de expresión de preferencias" (Torcal, 2000, p. 42), lo que, según el autor, genera nuevos tipos de relación entre ciudadanos, autoridades y la propia democracia representativa. En cambio, en las nuevas democracias los ciudadanos "no están adquiriendo actitudes positivas hacia las instituciones de la democracia ni una mayor implicación política” (Torcal 2005, p. 3), lo que queda en evidencia en gráficas y tablas presentadas en este trabajo.

De todas maneras, para ser precisos, necesario es indicar que esta no es una situación privativa de los jóvenes chilenos y de Chile en particular. Los datos de Latinobarómetro, en anteriores mediciones realizadas, nos muestran una tendencia inclusive a la baja: "entre el 2006 y el 2007 el promedio de apoyo regional cae de 58\% a 54\%" (2007, p. 79). Se solía pensar que el periodo de bonanza económica que hubo en la región sería una condición por si sola de apoyo, lo cual claramente no fue así y hay que ir a cuestiones más de fondo, pues “...la indiferencia y el autoritarismo no están ligados a la coyuntura económica, ni a la política, sino más bien parecen ser culturales y valóricas" (p. 79). Además, se podría decir que hay cierta incongruencia pues, por ejemplo, la percepción de la democracia apunta a que en Chile funciona mejor en comparación con los países vecinos, pero al mismo tiempo el chileno "tiene una visión muy crítica de su propia democracia, con altas demandas" (2008, p. 103), lo que podría ser bueno si hubiera proactividad y ganas de hacer cosas nuevas sin permitir que la institucionalidad pase por sobre la ciudadanía.

No obstante, la práctica indica lo contrario. La crítica se hace desde la comodidad de la casa, es una ciudadanía reactiva que se reúne en "jornadas de protesta" un par de veces en el año, generalmente son los mismos sectores (profesores, estudiantes, empleados fiscales, etc.) y los mismos temas que se han mantenido latentes en estas dos décadas de gobiernos democráticos. Sin embargo, en el último lustro han surgido otros grupos, como los ambientalistas, que han intentado instalar temas nuevos, unos con mayor éxito que otros, pero en general estamos hablando de un ciudadano que básicamente se reúne cuando ve que los problemas tocan su puerta, lo cual puede ser interpretado como una nueva forma de expresión ciudadana en cuanto a los problemas que la aquejan. La pregunta que surge es ¿̇cuánto colabora este tipo de manifestación a 
la profundización y mejoramiento de la calidad de la democracia? No tenemos por ahora la respuesta, sólo asumimos que se producen cambios que no sabemos adónde nos llevarán, hay que seguir investigando.

\section{A modo de conclusión}

En términos generales, podríamos decir que probablemente estemos asistiendo al agotamiento del modelo político basado en el consenso, de ahí que constantemente se hable de una crisis de representación. Los marcos cognitivos se han desconfigurado y el ciudadano no ve en la política lo que antaño, es decir, una actividad que conduce y que responde a sus inquietudes.

Esta política de consenso impide visualizar diferencias, toda vez que las campañas políticas, que es la época en la cual la clase política es más visible, están montadas sobre ejes discursivos, imágenes y programas muy similares, lo que ha llevado a que se extienda el sentimiento de que sea quien sea el que gobierne la vida continúa, lo cual serviría como una explicación del inmovilismo ciudadano.

Esto nos lleva a poner a prueba como investigadores nuestra capacidad de comprensión del fenómeno, a asumir que la realidad social es la suma de las diversas perspectivas individuales acerca de esa realidad y por tanto, hay más perspectivas que personas debido a los constantes cambios de percepción.

El mundo social es un mundo de construcción cognitiva; por ende, si han cambiado los marcos cognitivos, deberíamos preguntarnos si aquel modelo de democracia que se (re) instaló es el adecuado y si las percepciones ciudadanas son consonantes con las de la clase política. Ante esto creemos que hay un problema de adecuación entre el objeto conocido, nuestra supuesta tradición republicana y democrática, y el objeto por conocer, la democracia resultante del proceso de negociación con los militares. La desafección política podría estar representado una inconsistencia entre el lenguaje y el mundo, entre lo que se dice y la práctica cotidiana. En el sentido schutziano, la vida cotidiana, el mundo de la vida, presentaría un quiebre, esto en tanto que podríamos estar ante una falla sistémica en cuanto a que el equilibro actual está montado sobre un equilibrio anterior, dejado por los militares, lo que ha impedido dar solución cabal a problemas de fondo que han quedado latentes; es decir, la clase política sólo ha administrado un modelo que le ha sido funcional a sus intereses.

De ahí la importancia de analizar el fenómeno de la desafección política adecuado a la realidad del Chile post autoritario. Para dar cuenta de él, para poder explicarlo, es necesario comprender, lo que implica observar el fenómeno, y para poder hacer esto último hay que tener conceptos. El problema es que observar no es más sencillo que comprender, esto en función de que toda observación tiene carga teórica, prejuicios instalados que deben ser sometidos a crítica. La intersubjetividad que caracteriza 


\section{Roberto Mardones A}

las relaciones sociales nos fuerza a ser precisos, la complejidad de la investigación en ciencias sociales está fundada en que hay situaciones observacionales que producen cambios de percepción. Si bien el sentido común nos proporciona acuerdos previos acerca del mundo que nos rodea, la idea es investigar para producir conocimiento científico de ese sentido común para lo cual debemos, previamente, ponernos de acuerdo sobre el objeto observado.

Entonces podríamos decir que, en este caso, estaríamos frente a una discontinuidad entre el sentido común de la clase política versus el sentido común ciudadano, lo cual se vería reflejado en que "la insatisfacción de la ciudadanía está poniendo en cuestión la legitimidad política y el modelo democrático" (Oller, 2003, p. 15); esto está generando retrotraimiento ciudadano antes que formas alternativas de expresión, abriendo el espacio para que los partidos y grupos de interés cerrados y con poder copen la arena política y así decidan en función de sus intereses generando redes clientelares en las cuales el ciudadano común poco tiene que ver.

Lo anterior nos lleva a asumir que una cuestión importante a destacar de esta aproximación es la variable contextual. La historia política, los éxitos y fracasos que en el transcurso de esa historia hayan sucedido, sobre todo en cómo ha mutado la relación Estado - ciudadano y el sentimiento de pertenencia con dicha institución, es necesario tenerlos en cuenta para poder comprender el fenómeno. Por ejemplo, hay que considerar que no hay continuidad de la relación mencionada porque el Estado post autoritario tiene unas características que lo hacen diametralmente opuesto al existente antes de la instalación de las dictaduras militares. Para Latinoamérica en general, "las razones de la desconfianza son tanto debidas a su pasado, presente en algunos casos, de dictadura, oligarquías, autoritarismos, concepciones patrimonialistas del Estado, al igual que a un presente donde los sistemas políticos no logran generar confianza debido sobre todo a la ineficacia e ineficiencia de su funcionamiento" (Vásquez, 2002, p. 2).

De esta manera, al ser nuestra trayectoria histórica distinta a la de los países desarrollados, se genera un escenario político particular en el cual se mezclan elementos de continuidad y cambio, lo que nos lleva a plantearnos que quizás estemos ante un fenómeno que aunque se puede rotular como desafección política está más relacionado con la alienación o con una graduación del fenómeno dentro de un contexto de democracias reinstaladas y con procesos inconclusos tras la transición que no permiten su consolidación; esto contestaría tentativamente nuestra pregunta inicial ¿qué es la desafección política?

Esto es posible debido a que no hay involucramiento en la política convencional y tampoco se está dando una profundización de mecanismos no convencionales para hacer política, es decir, estamos hablando de una desafección que no sólo es institucional sino que tiene características de desapego generalizado de toda actividad de índole política. Hay un cuestionamiento al sistema democrático no dentro del esquema del pensamiento 
crítico sino más bien dentro de un contexto no proactivo; estamos en un escenario de inmovilismo ciudadano, de cuestionamiento sin involucramiento, en resumen, de una alienación como apatía y en algunos sectores como alienación. Así pues, quisiéramos terminar con una definición declarativa de alienación: "Proceso mediante el cual el individuo o una colectividad transforman su conciencia hasta hacerla contradictoria con lo que debía esperarse de su condición”. El tema está abierto.

\section{Referencias Bibliográficas}

Adimark. (2009). Evaluación gestión del gobierno. Disponible en: http://www.adimark. cl/estudios/eggabrilog.act

Anduiza, E., Crespo, I. y Méndez, M. (1999). Metodología de la ciencia política. Cuadernos metodológicos 28. Madrid: CIS.

CIEPLAN (2008). Estudio nacional sobre partidos políticos y sistema electoral. Disponible en: http://www.cieplan.org/inicio/destacado_frame_sup_detalle. php?id_destacado=23

Latinobarómetro (2007). Informe Latinobarómetro. Chile. Disponible en: www. latinobarometro.org

Latinobarómetro (2008). Informe Latinobarómetro, Chile. Disponible en: www. latinobarometro.org

Latinobarómetro (2011). Informe Latinobarómetro, Chile. Disponible en: www.latinobarometro.org

Ferrando, J. (1976). Estudios de ciencia política. Madrid: Editorial Tecnos.

Instituto Nacional de la Juventud (2000). Tercera encuesta nacional de juventud. Disponible en: www.injuv.cl

Instituto Nacional de la Juventud (2003). Cuarta encuesta nacional de juventud. Disponible en; www.injuv.cl

Instituto Nacional de la Juventud (2006). Quinta encuesta nacional de juventud. Disponible en: www.injuv.cl

Instituto Nacional de la Juventud (2009). Sexta encuesta nacional de juventud. Disponible en: www.injuv.cl

Instituto Nacional de la Juventud (2012). Jóvenes y las próximas elecciones municipales. Revista RT. Disponible en: www.injuv.cl, pp. 8-11.

Lechner, N. (1994). Los nuevos perfiles de la política. Un bosquejo. Revista Nueva sociedad, 130, 32-43. 
Luna, J. y Seligson, M. (2007). Cultura política de la democracia en Chile: 2006. Santiago: Pontificia Universidad Católica de Chile.

Luna, J. y Zechmeister, E. (2010). Cultura política de la democracia en Chile: 2010. Santiago: Pontificia Universidad Católica de Chile.

Madrid, S. (2005). “¿Políticos de ayer, apáticos de hoy? Generaciones, juventud y política en Chile”. En: C. Fuentes y A. Villar (Eds.), Voto ciudadano: debate sobre la inscripción electoral (pp.45 - 83). Santiago: FLACSO.

Montero, J., Gunther, R. y Torcal, M. (1999). Legitimidad, descontento y desafección. Revista del centro de estudios públicos, 74, 107-149.

Morales M. (2008). Evaluando la confianza institucional en Chile. Una mirada desde los resultados LAPOP. Revista de ciencia política, 28(2), 161-186.

Nohlen, D. (2008). Conceptos y contexto. En torno al desarrollo de la comparación en ciencia política. Institut de Ciences Politiques i Socials, working paper 265, 1-40.

Oller, D. (2003). El declive de la política: la crisis del espacio y del sujeto políticos. Frontera, 25, 15 - 38 .

Ostrogorski, M. (2008). La democracia y los partidos políticos, Madrid: Editorial Trotta.

Paramio, L. (1999). Cambios sociales y desconfianza política: el problema de la agregación de preferencias. Revista española de ciencia política, 1, 81-95.

Parker, C. (2003). Abstencionismo, juventud y política en Chile actual. Revista de estudios avanzados interactivos, 4, 1-23.

Programa de Naciones Unidas para el Desarrollo (2003). Desarrollo Humano en Chile, nosotros los chilenos: un desafío cultural. Santiago: PNUD.

Real Academia Española (2001). Diccionario de la lengua española. Disponible en: www.rae.es

Sartori, G. (2000). Política: lógica y método en las ciencias sociales, México: Fondo de Cultura Económica.

Toro, S. (2007). "La inscripción electoral de los jóvenes en Chile. Factores de incidencia y aproximaciones al debate”. En: Fontaine, A. (Ed.). Modernización del régimen electoral chileno (pp. 101-122). Santiago: PNUD.

Toro, S. (2008). De lo épico a lo cotidiano: jóvenes y generaciones políticas en Chile. Revista de ciencia política, 28(2), 143-160.

Torcal, M. (2001). La desafección en las nuevas democracias del sur de Europa y Latinoamérica. Instituciones y desarrollo, 8-9, 229-280. 
Torcal, M. (2005). Partidos y desafección política. Disponible en: http://www.grupochorlavi.org/php/doc/documentos/desafeccion.pdf.

Vásquez, R. (2002). El problema de la desconfianza institucional como freno a la gobernabilidad: América del Sur frente a las democracias occidentales. Disponible en: http://unpan1.un.org/intradoc/groups/public/documents/CLAD/ cladoo43415.pdf

Welzel, C. e Inglehart, R. (2009). El rol de la gente común en la democratización. Journal of democracy en español, 1, 174-190. 
